\title{
Utilizing Q-Methodology for the Study of the Behavior of the Audience of Creativity
}

\author{
Maria I. Munoz-Blanco ${ }^{1} \&$ Maria Antonia Padilla Vargas ${ }^{1}$ \\ ${ }^{1}$ Centro de Estudios e Investigación en Comportamiento, University of Guadalajara, Guadalajara, Jalisco, \\ México \\ Correspondence: Maria Antonia Padilla Vargas, Centro de Estudios e Investigaciones en Comportamiento, \\ Universidad de Guadalajara, Francisco de Quevedo 180, Col. Arcos Vallarta, Guadalajara, Jalisco, C.P. 44130, \\ México. E-mail: tony.padilla2008@gmail.com
}

Received: January 24, 2017

Accepted: February 22, 2017

Online Published: March 15, 2017

doi:10.5539/ijps.v9n2p67

URL: http://doi.org/10.5539/ijps.v9n2p67

\begin{abstract}
The study of Creativity from the standpoint of the Audience (e.g., any person that assesses a product as creative) has not been addressed yet from a naturalistic perspective in terms of the reactions of the individual according to the cultural group he/she belongs to. In this paper, a cultural group is defined as a group of individuals that have similar reactions to a stimulus (i.e., considering architectural objects as more creative than other objects). The present study presents a way to study Creativity from an interbehavioral standpoint by utilizing Q Methodology to capture the interaction between the Audience and the object. Thirty Participants (15 females and 15 males) from different occupations (art, science and various trades) were asked to organize sixty pictures (architecture, photography and furniture) in a Q-sort in terms of how creative they considered the picture was with respect to the others. The responses were grouped by three factors: photography preference, furniture preference and preference for architectural products. The results showed that the responses of the participants grouped them independently of their occupation or gender; showing specific tendencies on which objects they valued as most creative. Results are discussed in terms of how the factors represent the different cultural groups present in the participants' sample, and their relation with previous research on the behavior of the Audience. The present results show promise of the use of the Q Methodology in the research of the behavior of the Audience from a naturalistic perspective.
\end{abstract}

Keywords: creativity, cultural behavior, audience, Q-sort, interbehaviorism, Kantor

\section{Introduction}

Creativity has been studied from different perspectives in psychology, but it has been an elusive term for naturalistic psychology (Kantor, 1953). This perspective was defined by Kantor (1924/1926) as the study psychological events not only through direct observation but also by verifying the correctness of the observation by suitable methods (p. 1). One of the premises of naturalistic psychology is that only actually occurring phenomena are observed, and interpretations should be based on a complete a description of the facts.

In order to study creativity from this perspective, it is necessary to analyze how this phenomenon occurs. First, an individual whose behavior or behavioral product is labeled as "creative", this individual will be the Creator. Second there is an individual or group of individuals that label this behavior as creative, this will be the Audience. By doing so, the Audience labels the Creator as such, in the sense that the Creator is defined as the person that creates (Merrian-Webster.com, 2016). It is important to emphasize that the term Audience is used here to refer to any individual that labels a behavior or behavioral product as creative, not a professional art critic. The distinction between Creator and Audience is kept only for analytical purposes given that the Creator can function and its own Audience and as such shape its own behavior, similarly as Skinner (1974) described in as self-management.

The label "creative" is not considered a universal trait in which only characteristics of the behavior or behavioral product are taken into account, but as a relative term used depending on the Audience's cultural group, environment, among others as well as characteristics of the behavioral product. By doing so, this approach understands creativity as two interactions: the interaction of the Creator with the stimulus object, and the 
interaction of the Audience with respect to that interaction and/or the subsequent behavioral product (Muñoz-Blanco, 2014). Hence, a product is labeled "creative" after both interactions occur (Note 1).

In this case, unlike other behaviors such as pushing a lever, walking to the store, etc., that can be determined just in terms of its function, creative behaviors and creative products are not considered as such until an, an Audience interacts with them. Unfortunately, the behavior analytical literature has had little to say about the behavior of the Audience as it will be presented in the next section.

\subsection{The Importance of Studying the Audience}

Epstein (1980) argued that novel behavior occurs before a community labels such behavior or behavioral product as "creative". Behavior is considered novel when it is not part of the repertoire of the organism. Further, he explained that the selection of the label "creative" is not mysterious and research should be focused on using objective measures to observe changes in behavior. Marr (2003) readdressed the research on Creativity by looking through the different studies done on behavior analysis and other areas of research. He argued that there were three basic issues to consider with respect of Creativity: the source of creative behavior (i.e., heredity of creativity), individual differences in creative behavior (i.e., the characterization of a creative personality that allows for understanding differences in creative behavior), and the reason why some behavioral products are more valued or influential than others. Unfortunately, he only discussed the first two issues in his paper and focused on the empirical evidence that has shed some light into these issues. Unfortunately, references to the behavior of the Audience from this line of research this scarce and outdated, leaving this area of research almost unexplored.

From an interbehavioral perspective there is not too much research either, Carpio (1999) acknowledged that the standard by which a product is called creative is not static or universal but is continuously modified by evolving processes. This standard is specific to the social context in which it is presented and it also gets influenced by the creative behavior of the individuals involved. However, Carpio argued that the psychological study of Creativity should be done independently of social validation given that the standards to assess Creativity are always changing. This author argued that the study of Creative behavior in the laboratory should focus on the variables that make the Creator define a criterion different from the one presented in the task. In other words, Carpio argued that Creative Behavior is not novel within the parameters of the task but it changes the task itself. In sum, the position presented by these authors (Epstein, 1980; Marr, 2003; Carpio, 1999) although acknowledging the importance of the behavior of the Audience to understand Creativity, has dismissed it given the changing nature of this behavior.

Muñoz-Blanco (2014) argued that the study of Creativity will never be complete unless the role of the Audience is taken into account by the researchers and not left for other disciplines. Nonetheless, the behavior of the Audience needs to be understood in terms of the social environment in which it was acquired given that this behavior does not depend only on the own individual's own history but on the reactions of the community with respect to different objects that are labeled "creative" by it. One way to explore this aspect of the behavior of the Audience is by considering Kantor's theory.

\subsection{Kantor's Cultural Psychology and Creative Behavior}

Kantor, father of interbehaviorism, was concerned with developing a form of psychology that would be compatible with other sciences, in other words, to what he considered a naturalistic perspective (Kantor, 1953). He proposed that a naturalistic form of psychology should study the behavior of the organisms in terms of its interaction with the environment, removing explanations that include non-observable events. As such he suggested ways to understand topics that have been dealt by different lines of psychology, such as cultural psychology.

Kantor's cultural psychology is defined as a sub discipline of psychology that is concerned with the reactions that are shared by a group of individuals (Kantor, 1982). Cultural behavior refers then to common actions with respect to shared stimulational functions for members of a cultural group. In this case, it refers to all the different behaviors that are acquired by an individual as part of its cultural environment. A cultural group is hereby defined as a group of individuals that share the same responses with respect to a stimulus. An example of a cultural group is Americans who share a number of responses to stimuli like the American flag and the National Anthem. These responses do not correspond to physical or chemical properties of the stimuli but are acquired by their interaction with other members of the group. Given that now their responses to these stimuli are unified, they are now named Institutional Stimuli, to emphasize how they are different from other stimuli (i.e., chairs, doors, etc.). 
It is important to clarify that Kantor's theory of Cultural Psychology is different from the one proposed from Social Psychology. Kantor $(1953,1982)$ argued that psychology should focus on understanding the behavior of the individual, while in Social Psychology there is concern in understanding the behavior of groups and communities that develop signs and symbols. Kantor (1982) compared the relationship between cultural behavior and anthropological studies with the relationship between a grammarian's survey of language and speech behavior. He considered that part of the study of psychology was to connect the behavior features of cultural systems with the actual responses of the individual (p. 93). Within this context, Kantor argued that objects and conditions that have common and generalized functions are institutional stimulus, and these can be used to understand cultural responses. This approximation to Cultural Behavior opens the possibility for behavior analysts and interbehavioral psychologists to approach this form of group behavior without compromising the subject matter of naturalistic psychology, which is studying individual's behavior. This is particularly relevant for the study of the behavior of the audience.

One type of cultural behavior identified by Kantor (1982) is aesthetic behavior, which is the way that an individual behaves with respect to objects and events in terms of shared functions with its cultural group. Aesthetic behaviors include recognizing objects or events as creative. Although Kantor did not conduct research in the area, he suggested that one could study aesthetic behavior by presenting the institutional stimuli from a cultural group to another cultural group and studying how these reactions occur. This perspective opens the possibility to understand the behavior of the Audience within the realm of behavioral and interbehavioral psychology. In order to do this, it is necessary to capture the interaction of individual members of a cultural group with respect to institutional stimuli from same and different cultural groups.

\subsection{Previous Studies of the Behavior of the Audience}

The study of the behavior of the Audience is not new in the history of psychology. Guilford (1950) defined Creativity as a normally distributed set of traits, which led researchers to assume that creative products share these traits in different proportion. Consequently, this led several researchers from Social Psychology to look for these traits by studying the behavior of the Audience, which they called the "problem of the criterion" (Besemer \& Treffinger, 1981). This problem has been addressed in creativity in areas of advertising (i.e., Smith, Chen, \& Yang, 2008), culinary products (i.e., Horng \& Lin, 2009), and art (Besemer, 1998), among others. Their efforts have led them to define three dimensions of creativity: novelty, resolution, and elaboration and synthesis. Some others have been interested in characteristics of the audience in terms of their personality and intelligence (i.e., Storme \& Lubart, 2012), age (i.e., Knight \& Parr, 1999), as well as the capacity of generating original ideas (i.e., Hood Jr., 1973), among others. These studies describe which common or uncommon characteristics the audience as individuals have but shed no light on how these judgements are formed. In other words, they have not studied how the individual reactions to the products are acquired and change over time, leaving this aspect of the behavior of the Audience unexplored.

From the behavior analytic literature, Sloane, Endo and Della-Piana (1980) suggested that the label "creative" occurs when the person is not only taking into account the response characteristics or the form of the product, but also the variables that suggest the stimulus control leading to a creative product. They differentiated between two kinds of stimulus control: formal and informal. Formal control would correspond to behaviors and behavioral products whose form is determined by the community. In other words, they had been reinforced by the community. Informal control appears when the behavior or behavioral product's form is not determined by the community. In the latter case, an Audience is likely to label the behavior of the Creator as "creative" as long as he/she can recognize some of the controlling variables that led the Creator to behave in such a way. They argued that if the Audience is unable to discriminate the controlling variables they will label this behavior as "crazy". Goetz (1989) wrote on the topic of studying creativity in children and criticized Sloan's et al. (1980) theory by arguing that it is unrealistic to consider informal stimulus control when considering other populations such as children. Unfortunately, no other authors continued with the line of research suggested by Sloan et al. (1980).

In sum, the research done in the behavior of the Audience can be divided into two main topics: characteristics of the artistic stimuli that make them creative and variables that controlled the behavior of the Creator as perceived by the Audience. However, this research has focused on only in one of two aspects of the interaction, the stimulus object or the response. A naturalistic perspective of the behavior of the Audience needs to understand it as an interaction between the organism and different institutional stimuli. 


\subsection{Towards a Naturalistic Study of the Audience}

The literature reviewed showed different efforts to understand Creativity and art appreciation. However, this research focused on the understanding of Creativity in terms of how people agree on it, leaving out the study of individual how reactions to institutional stimuli are developed. As discussed earlier, there has been a lack of research on the behavior of the Audience from a naturalistic point of view. In particular, Kantor's (1982) suggestion on studying cultural behavior has been unexplored. As a consequence, there is a need to understand the behavior of the Audience in terms of its interaction with the artistic product by evaluating individual performances. In order to do this, the Q-methodology was tested to observe if it could be utilized as a tool to capture this interaction and to determine if this tool is appropriate for the study of the behavior of the Audience from a behavioral and interbehavioral perspective.

The Q-Methodology provides a holistic approximation of the behavior of the Audience in terms of individual reactions of a group of stimuli. This methodology incorporates the notion of the operant as proposed by Skinner and the interbehavioral field from Kantor's perspective (Delprato \& Brown, 2002). Developed in 1935 by Stephenson, the Q-Methodology consists in a way to study subjectivity by ordering a sample of items from one topic (Van Exel \& Graaf, 2005). The main aspect on the Q-Methodology is the Q-sort technique that consists in a rank-ordering set of stimuli within a continuum. Participants interact with the Q-sort and organize stimuli in a table, allowing measuring attitudes with respect to the group stimuli in a holistic way. This method uses a progressive forced-choice organization of the different stimuli, while creating a quasi-normal distribution. This organization highlights how each of the items is interdependent with each other. Data is analyzed by using a factor analysis which organizes individual responses into factors.

This methodology was selected for the present study because it captures the interaction of the Audience with different artistic products when the products are presented in a group and not individually, as well as permitting the organization of participants in terms of their responses with respect to institutional items, clustering them according to their cultural group. Another advantage of using this methodology is that the results are only valid within the group selected for the study. It allows understanding the differences between and among groups by only considering the responses of its individuals in relationship with other responses and not with respect to a norm or standard. Hence, using the Q-methodology does not provide a standard on how members of certain group behave with respect to the different items but it gives us an understanding on how the members of the group relate to each other with respect to their interaction with those stimulus. This position coincides with Kantor's (1982) perspective on cultural behavior which is identified with respect to similar behaviors from other members of the same cultural group.

In addition, one of the aims of the present study was to extend previous research done in the area from behavior analytical accounts. In order to do this, a questionnaire was included to explore how the participant described the object selected as more creative and how it related the work of the artist with its own work. These questions were designed to explore Sloane's, Endo's \& DellaPiana's theory on the effect of the perceived control by audience for the label "creative" to be emitted.

The purpose of this study was to develop a Q-sort to test if the interaction between the behavior of the Audience and institutional stimuli from the art community can be captured. Stimuli were selected from three different artistic forms based on art contests in which creativity was used as criteria: photographs, furniture, and architecture. The sample of individuals was taken based on their art training and their familiarity with using a criterion, to do this three social groups were taken into consideration: art students (i.e., Art group), to represent participants trained in art as well as using criteria to judge art; doctoral students in behavior analysis were selected for their experience using precise criteria in science but their lack of formal training in art and (i.e., Science group), finally a group of individuals that reported not being formally trained in art and to have no experience using predetermined criteria to judge objects was selected (i.e., Various Trades group). These groups were selected to explore the effects of training and experience with criteria judgment following Kantor's (1982) suggestion to understand cultural behavior in terms of the interaction of a variety of Audiences with institutional stimuli of different cultural groups, in this specific case, art groups.

In sum, the present study is exploratory with respect to the usefulness of the Q-methodology in a naturalistic approximation to the behavior of the audience of creative products and behavior labeled as creative. As a secondary aim, participant's different occupations are compared to observe if having specific training in art or science corresponds with the cultural groups identified by the Q-sort. Finally, the participants' factor grouping in the Q-sort is analyzed to observe if there is a particular preference to a type of stimuli used in this study (architecture, photography and furniture design). 


\section{Method}

\subsection{Participants}

Thirty adults (15 males and 15 females) over 18 years-old, whose first language is Spanish, were selected according to their occupation: 10 were art students (Art Group), 10 were doctoral behavioral science students (Science Group), and 10 untrained in arts and science with different occupations (Various Trades Group). Participants were selected according to their art training and their familiarity with the use of formal criteria to judge objects, as described in the introduction. Their participation was voluntary and they signed a participation form before the study.

\subsection{Instruments}

60 pictures were selected from different international creativity awards. These pictures corresponded to three categories (20 in each category): photography (Creative Asia and Sony World Photography Awards, 2015), furniture (A' Design Awards \& Competition, 2013-2015) and architecture (Pilsker Award, 1979-2014). The Q-sort board was depicted in a $120 \times 60 \mathrm{~cm}$ cardboard with the silhouette for the pictures to be arranged (see Figure 1). The study was conducted in a large room with a table where all of the photographs were displayed. A chair for the participant to sit in during the questionnaire portions faced the Q-sort board. The board was located on one of the walls with a one-way mirror on the opposing side.

In addition, an Interest in Art questionnaire was developed to assess current behaviors that demonstrated participants' interest in art related activities, this questionnaire was based on the description made by Hekkert and Van Wieringen (1996) (see Appendix A). Questionnaire A was designed according to the parameters identified by Sloane et al. (1980) for the label of "creative". In this questionnaire, participants were asked about the function of the picture that they selected as most creative as well as to identify the controlling variables that may have been involved in the behavior of the artist (see Appendix B). These questionnaires were intended to serve as surveys of participant's opinion.

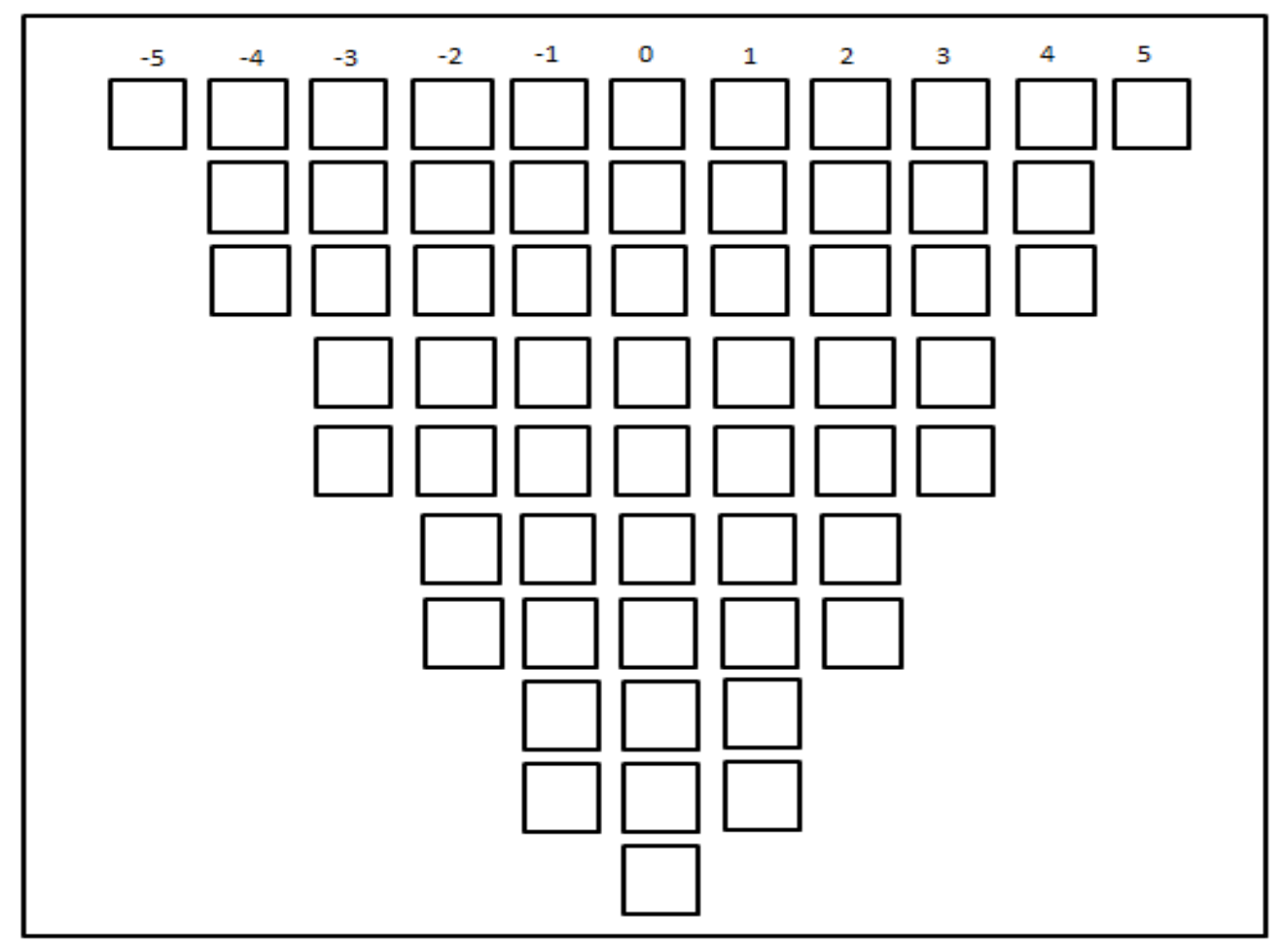

Figure 1. Q-sort board-Cardboard layout for picture organization 


\subsection{Procedure}

The photographs were laid out on the table before the participant arrived and three trays were positioned on the side with a sign for "creative", "neutral" and "non-creative". The study consisted of three parts: Art interest questionnaire, picture Q-sort, and interview and questions with respect to the performance. All participants were exposed individually to all parts of the study and to the same stimuli.

Once the participant agreed on participating, an art questionnaire was presented and the participant was left alone until he/she was done. For the second part of the study, the participant was oriented to the photographs and the trays. A paper copy of the first set of instructions was given to the participant and read out loud.

Welcome and thank you for participating. The present study has as an objective to identify why a person considers an object as creative.

This study has three phases. During the first phase, we're going to give you a set of photographs and we'll ask you to organize them into three groups: creative, neutrals, and non-creatives. Keep in mind that we're asking to organize them according to what YOU consider to be creative. There is no right or wrong choices.

I will be waiting outside. Please let me know when you are done organizing the photos.

After this, the participant was left alone in the room. Once the participant finished, the researcher went into the room and gave a new set of instructions to the participants as follows:

Thank you for organizing the photos. Now I need you to use this diagram to organize them in a more specific way.

As you can see, in this diagram there are numbers on the top. You need to organize the photos according to this system. Place the photo that you consider to be less creative of all into the -5 slot. Likewise, place the photo that you consider the most creative into the 5 slot. The 0 column will be for those pictures that you consider the most neutral. Use the other columns to organize the rest of the photos into the spectrum.

Remember, there are no correct answers. You can reorganize the photos until you are satisfied with your organization. You should not leave empty boxes or put a photo outside of the spaces provided.

I will be outside, please let me know when you are done organizing the photos.

The participant was once again left alone in the room and video was recorded from the observation room. Once the participant was done, the third part of the study began. The participant was asked to sit by the table facing the Q-sort diagram and questionnaire A was given to the participant (see Appendix B). The participant was left alone in the room until finished.

\section{Results}

The present study aimed to explore the behavior of Audiences from different cultural groups (Science, Art, and Various Trades) with respect to institutional products of Architecture, Furniture Design and Photography in order to evaluate the usefulness of the Q-methodology to study the behavior of the Audience was evaluated. It also aimed to assess if the occupations of the participants (training in art or science) corresponded with the cultural groups identified by the Q-sort. Finally, the analysis of the data collected by the Q-sort was done to assess if there was a particular preference by the participant to certain type of institutional stimuli.

\subsection{Statistics and Data Analysis}

Participants' results from the Q-sort were grouped into four factors as shown in Figures 2, 3, 4 and 5.

The analysis of the Q-sort data was done by doing a factorial analysis using the PQMethod 2.35 program developed by Peter Schmolck, adapted from Mainframe-Program QMethod by John Atkinson at KSU (2014). In order to do this, the program assigned numbers to each of the images according to the organization on the board (i.e., if an image was placed on the -3 column, it would be assigned a -3 score) and later organized participants responses into factors according to similar scores given to the images. Given that the Q-sort board mimics a normal distribution, Z-scores were calculated to create an ideal sort for each of the factors and understand what type of stimuli the participants in each factor favored. Higher Z-scores corresponded with stimuli that were valued as more creative. Factors with an eigenvalue higher than 1.00 were selected to be reported according to the standard of this methodology (Watts \& Stenner, 2005). 
Data collected from the Interest in Art Questionnaire (see Appendix A) was analyzed by scoring each of the items. Score criteria for this questionnaire was calculated by adding the scores of the participants in the questionnaire, and interpreted according to the criteria shown in Appendix C.

Factor 1 has 13 significantly loading participants and it explains 30\% of the study variance. It has an eigenvalue of 4.85, eight of the participants in this factor are females and five are males. Participants in this group scored photography images higher, while furniture and architecture were scored as less creative (see Figure 2). They scored average on art interest $(n=10)$ and reported to be able to do an identical or similar product in the image they considered as more creative $(n=8)$.

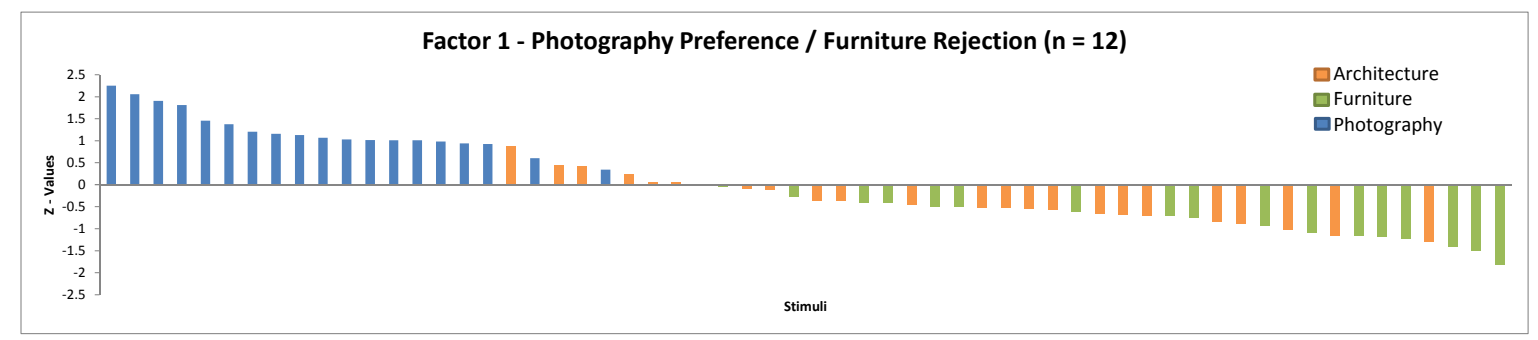

Figure 2. Z-scores for items distribution in Factor 1

The second factor that was extracted has 9 significantly loading participants and it explains $20 \%$ of the study variance. It has an eigenvalue of 3.22, and grouped two females and seven male participants. These participants scored furniture items higher, while considering architectural and photography products less creative (see Figure $3)$. They scored average on the art interest questionnaire $(n=6)$ and reported that they would be able to produce the item they considered to be more creative $(n=5)$.

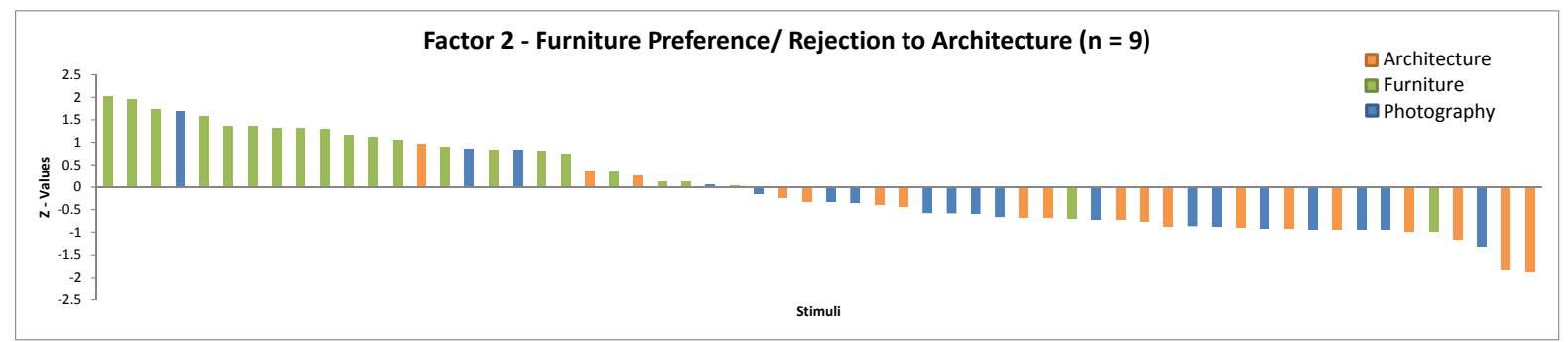

Figure 3. Z-scores for items distribution in Factor 2

The third factor has 4 significantly loading participants, explaining $10 \%$ of variance. It has an eigenvalue of 1.58 participants consisted in three females and one male. Participants grouped in this factor showed that they scored photography products as less creative than the other categories, valuing more furniture products (see Figure 4). These participants reported that they wouldn't be able to produce the same item they chose as more creative $(\mathrm{n}=$ $3)$.

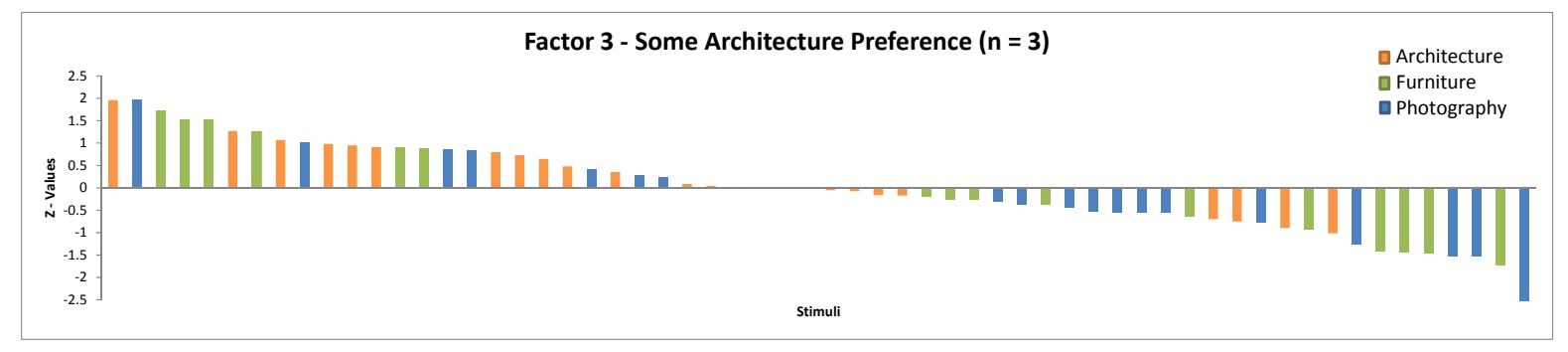

Figure 4. Z-scores for items distribution in Factor 3 
Factor 4 has two significantly loading participants that explain $8 \%$ of variance. It has an eigenvalue of 1.23 and consisted of one female and one male participant. Participants grouped in this factor were characterized for scoring higher than the other participants in the interest in art questionnaire and belonged to the Art Students group. They showed a preference to photography as well as some other products from furniture and architecture (see Figure 5). Unlike participants on Factor 1 that also showed preference to photography items, these participants also selected furniture and architectural products as creative. These participants argued that they would be unable to produce a similar product as the one they considered more creative.

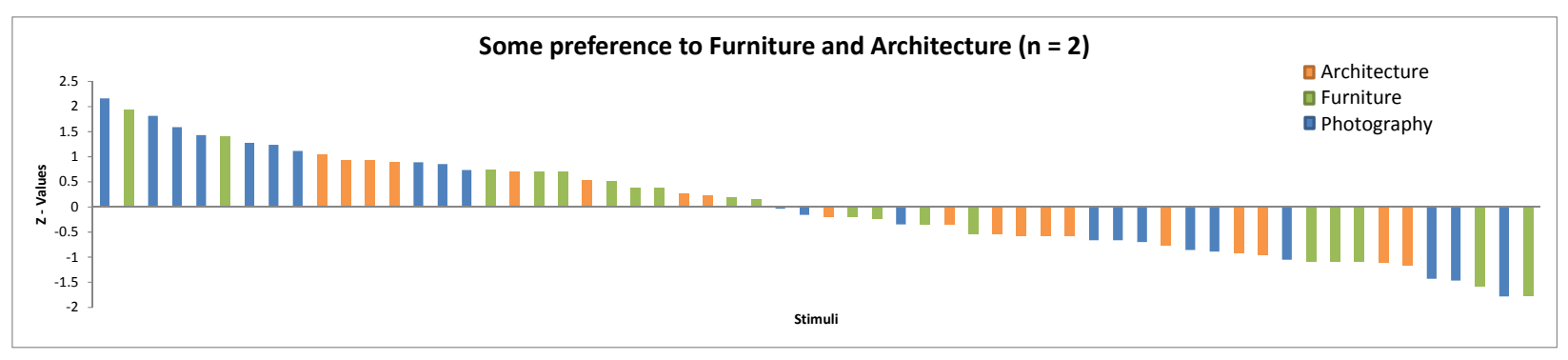

Figure 5. Z-scores for items distribution in Factor 4

Two participants were left out of these four factors. These participants were considered outliers and were not taken into account for further analysis. Descriptive statistics were calculated with respect to the loading of each of the participants for each factor, as well as the participants loading to the factor according to their occupation (see Table 1).

A one-way ANOVA was conducted to compare if the participants' occupations had an effect on their loading into factors 1 to 3 (see Table 1). Factor 4 was not included given that it had only 2 significantly loading participants, insufficient for a proper analysis, and both participants belonged to the Art group. An analysis of variance showed some effect of occupation on having a significant factor load in Factor 1, F $(2,10)=2.25, p$ $=.155$ (Note 2). Looking at the values of the means for factorial saturation (see Table 2); the science group had a greater factorial saturation compared to the other two groups. No other significant differences were found with respect to factors 2 and 3 on the participants' occupations and their loading into their corresponding factor, results of the one-way ANOVA for these are shown in Table 1 and descriptive statistics are shown on Table 2.

Table 1. One-way ANOVA comparing participant's occupation effect on the loading to the factor the participant belonged to

\begin{tabular}{llll}
\hline & F & Significance & Degrees of Freedom \\
\hline Factor 1 & 2.25 & .155 & 2 \\
Factor 2 & .335 & .728 & 2 \\
Factor 3 & .109 & .773 & 2 \\
\hline
\end{tabular}

From questionnaire A, participants were asked to circle which words would they use to describe the image that they considered more creative (i.e., on 5 in the Q-sort board). These results are shown on Table 3, which reveals that most participants used the word creative to refer to the image as well as the words Fantastic, Novel and Useful. Also, data from the open ended questions were coded and organized in terms of similarity of responses (Appendix D).

Questionnaire A asked participants to identify the functionality and controlling variables of the item that they identified as more creative. Results showed that participants in Factor 1 reported that possibly the art piece served to send a message in order to have a particular effect on the public (i.e., "the importance that music has that even in the middle of chaos, worry or other similar sentiments") or it had functions according to itfs artistic properties (i.e., "aesthetically complex piece"). Different functions were identified by participants in Factor 2 such as aesthetic functions (i.e., "decoration, comfort and style") and problem solution functions for the art piece (i.e., "it is very useful to have everything organized, have [books] at hand and not all over the place"). Different 
functions were identified by each of the members of Factor 3 with no particular trend. On the other hand, members of Factor 4 reported that the art piece served to solve a problem (i.e., "Home and room, it activates the senses"). Factor's distribution on the different categories is shown on Table 3.

Table 2. Descriptive statistics for the participants grouped in the different factors according to their occupation

\begin{tabular}{llccc}
\hline Factor & \multicolumn{1}{c}{ Occupation } & N & Media & Standard Error \\
\hline Factor 1 & Sciences & 5 & .745 & .046 \\
& Arts & 6 & .596 & .039 \\
& Various Trades & 2 & .595 & .177 \\
& Total & 13 & .653 & .037 \\
Factor 2 & Sciences & 3 & .699 & .065 \\
& Arts & 2 & .145 & .108 \\
& Various Trades & 4 & .076 & .038 \\
& Total & 9 & .663 & .032 \\
& Sciences & 1 & .542 & - \\
& Arts & 3 & .578 & .054 \\
& Various Trades & 0 & - & - \\
& Total & 4 & .569 & .039 \\
& Sciences & 0 & - & - \\
& Arts & 2 & .642 & .078 \\
& Vactor 4 & 0 & - & .648 \\
& Total & 2 & .642 & \\
& & & &
\end{tabular}

Participants were also invited to estimate what they considered were the controlling variables for the behavior of the Creator while doing the art piece they selected as most creative. Participants in Factor 1 were more likely to identify a problem given to the artist (i.e., "an architect asked the artist to do it") or a particular artistic effect (i.e., "an analysis of necessities and a purpose of innovation") as the controlling variables for the artist. On the other hand, participants in Factor 2 were more likely to identify the artist's own personal experiences as the controlling variable (i.e., "the artist appreciated how great it is to live and the love of our loved ones that surround us"). Finally, half of the participants in Factor 3 and all of the participants of Factor 4 identified a problem as the possible controlling variable for the Creator of the art piece (see Table 3).

Table 3. Participant's responses to Questionnaire A distributed per factor

\begin{tabular}{cccccc}
\hline & Factor 1 & Factor 2 & Factor 3 & Factor 4 \\
\hline Words to Describe & Creative & 10 & 8 & 2 & 2 \\
& Fantastic & 6 & 5 & 2 & 0 \\
Novel & 4 & 6 & 1 & 1 \\
Useful & 4 & 4 & 2 & 2 \\
Usual/Normal & 1 & 0 & 0 & 0 \\
Senseless/Crazy & 1 & 0 & 0 & 0 \\
Bunctionality & Boring or Useless & 0 & 0 & 0 & 0 \\
& Effect in the Public/Message & 6 & 2 & 1 & 0 \\
\hline
\end{tabular}




\begin{tabular}{|c|c|c|c|c|c|}
\hline & Artistic Properties & 4 & 0 & 0 & 0 \\
\hline & Expression of Feelings & 2 & 1 & 0 & 0 \\
\hline & Aesthetic Properties & 0 & 3 & 1 & 0 \\
\hline & None & 0 & 0 & 1 & 0 \\
\hline \multirow[t]{6}{*}{ Artist' Reason } & History of the Artist & 3 & 5 & 0 & 0 \\
\hline & Solution of a Problem & 4 & 2 & 2 & 2 \\
\hline & Artist's inner purpose & 3 & 0 & 1 & 0 \\
\hline & Artistic properties of the product & 3 & 0 & 0 & 0 \\
\hline & Similarity with other artistic product & 0 & 0 & 1 & 0 \\
\hline & None & 0 & 2 & 0 & 0 \\
\hline
\end{tabular}

\section{Discussion}

Studies in Creativity from a behavioral and interbehavioral approach have usually focused on the study of the behavior of the Creator as the person whose behavior or behavioral product is considered creative. However, the behavior of the Audience as the person that identifies this behavior or behavioral product as creative has been neglected. The present paper aims to understand the individual behavior of the Audience based on Kantor's (1982) theory on cultural behavior as an effort to connect the literature of the Audience developed in other lines of psychology with a behavioral and interbehavioral approach.

Results from the present study showed that the Q-sort is a useful tool to identify the cultural groups according to their reactions to the different art representations. Also, these results showed that criteria such as gender and occupation are not representative of the cultural group the participants belonged to. Four factors were extracted from the participant's responses, representing $68 \%$ of the study variance and grouping 27 of the 30 participants. These factors showed that participants, despite their occupation or gender, grouped according to their preferences for either type of artistic product showing specific tendencies for their selection. These results are in agreement with the concept of Cultural group presented in this paper by which groups are determined by the responses of the individual and not by gender or occupation. This type of research differs from traditional approaches to cultural psychology from Social Psychology as discussed earlier, and provides a different outlook on the understanding of cultural behavior.

Some differences were found when looking at the results of the Interest in Art questionnaire in which participants grouped in Factor 3 scored lower than participants grouped in Factor 1 and 2, while participants grouped in Factor 4 grouped the higher. These results are in agreement with behavioral approaches to behavior that emphasizes how the history of the individual is what determines its behavior (Skinner, 1974); in this case, the history of the participants determined their own selection. It stands out how the history the individuals had with the own occupational group seemed to be irrelevant when organizing the different images.

The Questionnaire A was introduced to learn about the criteria that the participants' reported for their data analysis. Their results show that participants from different Factors used different aspects of the art pieces to organize them according to their perceived level of creativity. An interesting finding was that participants in Factor 1 were more interested in characteristics of the behavior of the Creator and the piece (i.e., innovation and skill) while participants in Factor 2 were more concerned on how they personally reacted to the art piece. These results are consistent with the literature on Social Psychology with respect to the characteristics of the Audience. Caroff and Besancon (2008) argued that independently of the design, participants do not modify the assessment of originality level on creativity ratings, suggesting that this aspect is specific of every individual. The present study confirms the differences found among participants with respect to their creativity judgements, as well as it shows that their grouping of responses also has correspondence with the criteria that they reported in Questionnaire A.

Given that the participants on each factor scored differently on the Interest in Art questionnaire, this finding is in agreement with Hekkert and Van Wieringen (1996) who studied expert and non-expert criteria to assess art, suggesting that independently of the interest in art (as in this study) or with respect to art training, participants on the same factor have agreements with respect to the criteria that they used to organize the pictures. 
The literature reviewed showed that for the most part, research on the Audience has focused on the characteristics of the piece that makes it creative, or on characteristics of the Audience. The present results show how focusing only on one of those aspects of the behavior of the Audience narrows the understanding of this behavior, opening then a field of study for behavioral and interbehavioral psychologists. Current research on the behavior of the Audience in other forms of psychology has proven to be useful for identifying characteristics of the object or the group that identifies it as creative, behavioral and interbehavioral approaches can then breach the gap between these two by helping to understand the interaction between the object's function and the response's function when the audience labels a behavior or behavioral project as creative.

The results of this preliminary study shows that the Q-methodology can be used as a viable method for understanding the behavior of the Audience as it develops and changes through time. The Q-methodology allows us then to understand the Audience as both an individual and as a member of a cultural group identified by each factor, following Kantor's (1982) proposal on Cultural Psychology. The behavior of the Audience as an individual is reflected in his responses to the different questionnaires, as well as the organization of the pictures in the Q-sort board. This latter one revealed how, although each way of organizing the items in the Q-sort was unique, the participant's response could be grouped with other responses from other participants, revealing the different cultural groups found in the participants. This finding opens up the study of cultural groups as defined by their responses in this task.

In order to explore the theory presented by Sloane et al. (1980) about the behavior of the Audience as a label controlled by the identification of the sources of control for the behavior of the Creator, Questionnaire A was created. The results of this questionnaire showed that the criteria identified by the participants grouped into one factor were different despite their occupation which correlated with their experience with art and the use of formal criteria to assess objects. This finding is in agreement with Kárpáti and Zempléni (1998) analysis of the differences found between judges on artistic contests. These authors argued that despite art education, judges always have "favorite criteria, which they consider more important than anything else" (p. 400). It seems then that the participants in the present study had certain criteria to organize all of the items but the selection for the most creative one corresponded to different criteria.

According to Sloane et al. (1980) the label "creative" is given when the individual identifies the originality or novelty of the stimulus assessed, in particular when the Audience can discriminate that the control is informal. Participants from the different factors reported believing that the artist had a previous purpose or was aiming to solve a problem for creating the image they selected as most creative. These reasons are independent of their preference for photography (Factor 1) or furniture (Factor 2) items, among others. This finding shows that unlike what was hypothesized by Sloane et al. (1980) participants not only identified originality or novelty when selecting the most creative item, but also used the words useful. Further, eight participants in Factor 1 and five in Factor 2 considered that given the opportunity they would be able to replicate or some of them mentioned to improve the item selected as most creative. This suggests that these participants did not considered the behavior of the Creator under informal control but by formal control in which if they were in the same situation they would have done the same. This becomes evident on the question related to the function of the piece, in which these participants were more likely to assume there was a request or a problem by which the creative product was the solution.

The model proposed in this paper suggests that creativity entails the analysis of two behaviors, the behavior of the Creator, and the one of the Audience. The present study sides on the Audience (Note 3) and its interaction with a behavioral product that has been considered creative by a group of experts in each field. The results given by the Q-methodology allows us to understand individual responses not only in terms of their own uniqueness but also as these groups with similar responses. As a consequence, this methodology allows for the enhancement of the understanding of creativity from behavioral and interbehavioral psychology by considering similar responses of individuals in the same group. The grouping that comes from the Q-sort allows identifying the different cultural behavior found within the participants, opening the field to research the suggestions that Kantor (1982) made on how to study the Audience's behavior. The findings presented also present a novel way to understand cultural behavior that is not defined by the groups on which an individual may belong to, but on how their responses to institutional stimuli are similar. Further discussion with respect to the definition of cultural behavior seems to be necessary.

Some limitations of this study pertain to the instructions for the Q-sort given that a few number of participants expressed their confusion over what they had to consider to organize the stimuli; the item inside the picture or the overall image. The instruction was non-specific given that previous research on creativity (see Carpio, 2005) has shown that in order to capture creativity it is necessary to not lead the participants into a particular response. 
Likewise, it was considered in this study that the instruction should be open ended to allow for free interpretation of it and to not lead the participant into a particular pre-conception of creativity prior the organization of images. Although, the participants' confusion was expected by the authors, this needs to be explored further.

Another limitation comes from the theoretical framework that directed the present study. Several other analyses can be made with the data gathered from this study that would answer questions from other forms of psychology, such as characteristics of the images that were selected by each group or behavioral characteristics of each of the participants. These analyses would definitely enhance the comprehension of the results described in this paper, nonetheless goes outside the scope of the paper and the expertise of the authors. Future collaborations with other disciplines should be done in other to fully capture all of the dimensions of the data collected through the Q-sort.

Future research should explore different aspects of the behavior of the Audience. Carpio (1999) discussed that the standard by which creative products are evaluated evolves around the social context and the individuals' creative behavior and because of this it was outside the subject matter of psychology. The present research shows that studying this evolution is now available for research by using the Q-sort methodology. This involves understanding how the behavior is acquired, developed and changed over time. Also, this can be used to understand how the Creator may function as its own Audience.

The present research opens a promising area that will enhance the research already done with respect to creativity and the behavior of the Audience from a naturalistic perspective, in particular but not limited to the interbehavioral perspective proposed by Kantor (1982). A naturalistic explanation will not further the idealistic understanding of creativity as it is something that cannot be understood, having almost magical properties (Marr, 2003), but will enable the understanding of the behavior as it occurs in the natural world without referring to non-existent entities. Further exploration of the Q-sort as a tool to understand the Audience's behavior to validate the results presented in this research and comparison between the behaviors of the members of the different cultural groups seems necessary to add to the understanding of the Audience's behavior.

\section{Acknowledgments}

This research was supported in part by PRODEP that provided the fellowship for Doctor Maria Isabel Muñoz-Blanco to join the laboratory of Dr. Maria Antonia Padilla Vargas at the University of Guadalajara. Also, the authors would like to thank Malia Mitooka and Robert Goodman for serving as expert judges and help in the elaboration of the instrument.

\section{References}

Besemer, S. P. (1998). Creative Product Analysis Matrix: Testing the Model Structure and a Comparison among Products-Three Novel Chairs. Creativity Research Journal, 11(4), 333-346. https://doi.org/10.1207/s15326934crj1104_7

Besemer, S. P., \& Treffinger, D. J. (1981). Analysis of Creative Products: Review and Synthesis. The Journal of Creative Behavior, 15(3), 158-178. https://doi.org/10.1002/j.2162-6057.1981.tb00287.x

Caroff, X., \& Besancon, M. (2008). Variability of Creativity Judgements. Learning and Individual Differences, 18(4), 367-371. https://doi.org/10.1016/j.lindif.2008.04.001

Carpio, C. A. (2005). Condiciones de Entrenamiento que Promueven Comportamiento Creativo: Un Análisis Experimental con Estudiantes Universitarios. Mexico, D. F.: Unplublished Thesis.

Carpio, C. (1999). La Creatividad como Conducta. In A. B. Ramírez (Ed.), Aportes Conceptuales y Metodológicos en Psicología Aplicada. México: Instituto Tecnológico de Sonora.

Delprato, D. J., \& Brown, S. R. (2002). Q Methodology and the Operant Construct. Operant Subjectivity, 25, 139-147.

Epstein, R. (1980). Defining Creativity. The Behavior Analyst, 3(2), 65.

Goetz, E. M. (1989). The Teaching of Creativity to Preschool Children: The Behavior Analysis Approach. In J. A. Glover (Ed.), Handbook of Creativity (pp. 411-428). Plenum Press. https://doi.org/10.1007/978-1-4757-5356-1_23

Guilford, J. P. (1950). Creativity. American Psychologist, 5(9), 444-454. https://doi.org/10.1037/h0063487

Hekkert, P., \& Van Wieringen, P. C. (1996). Beauty in the Eye of Expert and Nonexpert Beholders: A Study in the Appraisal of Art. The American Journal of Psychology, 109(3), 389-407. https://doi.org/10.2307/1423013 
Hood Jr., R. W. (1973). Rater Originality and the Interpersonal Assessment of Levels of Originality. Sociometry, 1, 80-88. https://doi.org/10.2307/2786283

Horng, J. S., \& Lin, L. (2009). The Development of a Scale for Evaluating Creative Culinary Products. Creativity Research Journal, 37(4), 54-63. https://doi.org/10.1080/10400410802633491

Kantor, J. R. (1924/1926). Principles of Psychology. Chicago, IL: Principia Press. https://doi.org/10.1037/10752-000

Kantor, J. R. (1953). The Logic of Modern Science. Chicago, IL: The Principia Press.

Kantor, J. R. (1982). Cultural Psychology. Chicago: Principia Press.

Kárpáti, A., \& Zempléni, A. (1998). Expert Agreement in Judging Art Projects-A Myth or Reality? Studies in Educational Evaluation, 24(4), 385-404. https://doi.org/10.1016/S0191-491X(98)00023-6

Knight, A. J., \& Parr, W. V. (1999). Age as a Factor in Judgements of Wisdom and Creativity. New Zealand Journal of Psychology, 28(1), 37.

Marr, M. J. (2003). The Stitching and the Unstitching: What Can Behavior Analysis Have to Say about Creativity? The Behavior Analyst, 1(Spring), 15-27.

Merriam-Webster, Inc. (2016). Merriam-Webster Dictionary: Creator. Retrieved August 2, 2016, from $\mathrm{http}: / / \mathrm{www}$.merriam-webster.com/dictionary/creator

Muñoz-Blanco, M. I. (2014). A Naturalistic Analysis of Creativity in Terms of the Behavior of the Creator and the Critic (Doctoral Dissertation, University of Nevada, Reno, USA). Available from ProQuest Dissertations and Theses (Accession Order No. 3638253).

Skinner, B. F. (1974). About Behaviorism. New York: Vintage Books.

Sloane, H. N., Endo, G. T., \& Della-Piana, G. M. (1980). Creative Behavior. Behavior Analysis, 3(1), 11-21.

Smith, R. E., Chen, J., \& Yang, X. (2008). The Impact of Advertising Creativity on the Hierarchy of Effects. Journal of Advertising, 37(4), 47-62. https://doi.org/10.2753/JOA0091-3367370404

Storme, M., \& Lubart, T. (2012). Conceptions of Creativity and Relations with Judges' Intelligence and Personality. The Journal of Creative Behavior, 46(2), 138-149. https://doi.org/10.1002/jocb.10

Van Exel, J., \& de Graaf, G. (2005). Q Methodology: A Sneak Preview. Obtenido de Q Methodology. Retrieved from http://www.qmethodology.net/PDF/Q-methodology

Watts, S., \& Stenner, P. (2005). Doing Q methodology: Theory, method and interpretation. Qualitative Research in Psychology, 2, 67-91. https://doi.org/10.1191/1478088705qp022oa

\section{Notes}

Note 1. There are several other interactions that occur during the time the Creator is behaving creatively, such as learning about other people's creative works, interacting with people that have been creative in the past, as well as being audience for other people's behavioral products. Nonetheless, the present paper focuses on the behavior of the Audience for analytical purposes.

Note 2. Significant values were considered when differences were found above $80 \%$ of the participants $(\mathrm{p}<.2)$.

Note 3. This audience can also be the creator when interacting with its own behavior and behavioral product.

\section{Appendix A}

\section{Interest in Art Questionnaire}

\section{Questionnaire}

\section{Gender:}

Age:

Occupation:

\section{Education Level: ( ) High school ( ) College ( ) Graduate Level}

Please, select the number that you consider goes with each affirmation according to each situation. Select 9 for "Strongly Agree" and 1 for "Strongly Disagree". 
Strongly Disagree Strongly Agree

$\begin{array}{llllllllll}0 & 1 & 2 & 3 & 4 & 5 & 6 & 7 & 8 & 9\end{array}$

I have a vast knowledge about art

I've been to museums, expositions and/or concerts this last year

As a child, my family taught me to appreciate art

I believe art is boring

In school I was involved in art groups

Art is for sophisticated people

I have a favorite painter/photographer/designer

I don't understand the differences among artistic manifestations

Someone in my family is an artist

I have friends that are artists

I know how to play and instrument or paint

Art is a way to waste time

Art is the only way to express feelings

I belong to groups interested in art

\section{Appendix B}

Questionnaire A

1) Please, circle the words that you believe are related to the artwork you placed on box number 5

$\begin{array}{ll}\text { Novel } & \text { Useless } \\ \text { Usual/Normal } & \text { Functional } \\ \text { Creative } & \text { Fantastic } \\ \text { Boring } & \text { Nonsense / Crazy }\end{array}$

2) What function do you think this artwork has?

3) How do you think the idea for this artwork came about?

4) If you were in similar circumstances with the necessary abilities and resources, would you have created the same art piece?

\section{Appendix C}

\section{Scoring for Interest in Art Questionnaire}

Table 4C. Scoring criteria for Interest in Art Questionnaire

\begin{tabular}{ll}
\hline Interest/knowledge in Art & Score \\
\hline Low & $0-48$ \\
Average & $49-96$ \\
High & $97-144$ \\
\hline
\end{tabular}




\section{Appendix D}

\section{Scale for Questionnaire A}

Table 5D. Scale used to categorize responses in Questionnaire A

\begin{tabular}{|c|c|c|}
\hline & Categorization & Description \\
\hline \multirow{6}{*}{ Function of the art piece } & Effect in the public/message & $\begin{array}{l}\text { Function is identified in the effect that the art piece has in the public: } \\
\text { feelings or send message }\end{array}$ \\
\hline & Problem solution & $\begin{array}{l}\text { A problem is hypothesized by the participant in which the art piece is } \\
\text { considered a solution }\end{array}$ \\
\hline & Artistic properties & $\begin{array}{l}\text { Characteristics on the art piece such as color, shape, dynamics among others } \\
\text { were identified as innovative from current artistic trends }\end{array}$ \\
\hline & Expression of feelings/ideas & The art piece is said to express feelings or ideas from the artist \\
\hline & Aesthetics & The art piece serves decorative purposes \\
\hline & None & Participant doesn't identify a function for the art piece \\
\hline \multirow[t]{6}{*}{ Reason behind the art piece } & History of the artist & $\begin{array}{l}\text { Previous experiences of the artist are identified as controlling variables for } \\
\text { the behavior }\end{array}$ \\
\hline & Solution of a problem & $\begin{array}{l}\text { A problem imposed by the community or the artist is assumed as the reason } \\
\text { for the art piece }\end{array}$ \\
\hline & Artist's purpose & $\begin{array}{l}\text { The artist's intention or will is identified as the cause for his/her behavior } \\
\text { that led to the art piece }\end{array}$ \\
\hline & Artistic purpose & Revolutionize or change the way artistic products have been done \\
\hline & Specific & A particular reason is identified as the controlling variable for the behavior \\
\hline & None & Participant reports not knowing the controlling variable \\
\hline
\end{tabular}

\section{Copyrights}

Copyright for this article is retained by the author(s), with first publication rights granted to the journal.

This is an open-access article distributed under the terms and conditions of the Creative Commons Attribution license (http://creativecommons.org/licenses/by/4.0/). 